\title{
Análisis e interpretación de la jurisprudencia sobre violencia familiar y sus efectos en las poblaciones vulnerables en el Perú
}

\author{
Analysis and interpretation of jurisprudence on family violence and its effects on vulnerable \\ populations in Peru
}

Alberto Rojas Alvarado

\section{RESUMEN}

Objetivo: Explicar cómo el tratamiento desde el punto de vista de la jurisprudencia y de las últimas modificatorias a la ley de violencia familiar, no satisface las expectativas de los justiciables en el Perú, un sector prefieren hablar de ineficacia, y con el fin de conocer cómo se vienen aplicando al resolver los casos prácticos, cotidianos por parte de quienes administran justicia, y las políticas públicas que sigue el gobierno, para luchar contra este flagelo, razón por la cual hubo la necesidad de realizar el presente trabajo de investigación. Material y Métodos: Se ha elaborado sobre la base del enfoque mixto, cualitativo por cuanto se analizó distintas teorías doctrinarias, jurisprudencias y normas, siendo el objetivo determinar en qué medida resulta eficaz el proceso por violencia familiar como garantía de protección de las víctimas. Es una investigación no experimental. Resultados: Muestran que se han expedido sentencias que contemplan dos variables: proceso de violencia familiar y la ineficacia de las medidas de protección, como garantía de protección de las víctimas. Conclusión: Los procesos de violencia familiar bajo el amparo de las ultimas modificatorias, no resultan eficaces como garantía de protección de las víctimas, por cuanto, no ha disminuido los casos de violencia, y más bien tiende aumentar, por factores como el aislamiento social obligatorio por efecto de la pandemia, políticas públicas deficientes, el no respeto a los derechos fundamentales conforme a la Constitución Política del Perú, a las convenciones y tratados internacionales de derechos humanos, quienes inciden en el respeto a los derechos de las personas y la familia.

Palabras clave: Proceso de violencia familiar, Ley de violencia familiar 30364, Ineficacia de la ley, Garantía de protección, Constitución y derechos fundamentales.

\begin{abstract}
Objective: Explain how the treatment from the point of view of jurisprudence and the latest amendments to the family violence law, does not satisfy the expectations of the defendants in Peru, a sector prefers to speak of ineffectiveness, and in order to know how they have been applied when solving practical, daily cases by those who administer justice, and the public policies that the government follows, to fight against this scourge, which is why it was necessary to carry out this research work. Material and Methods: It has been prepared on the basis of a mixed, qualitative approach since different doctrinal theories, jurisprudence and norms were analyzed, the objective being to determine to what extent the process for family violence is effective as a guarantee of protection of the victims. It is a non-experimental investigation. Results: They show that sentences have been issued that contemplate two variables: the process of family violence and the ineffectiveness of the protection measures, as a guarantee of protection of the victims. Conclusion: The processes of family violence under the protection of the latest amendments are not effective as a guarantee of protection of the victims, since it has not decreased the cases of violence, and rather tends to increase, due to factors such as compulsory social isolation due to the effect of the pandemic, deficient public policies, the lack of respect for fundamental rights in accordance with the Political Constitution of Peru, international conventions and human rights treaties, which affect respect for the rights of individuals and the family.
\end{abstract}

Keywords: Family violence process, Family Violence Law 30364, ineffectiveness of the law, guarantee of protection, Constitution and fundamental rights.

\section{INTRODUCCIÓN}

En este trabajo lo que se busca es conocer en determinar en qué medida la doctrina, la jurisprudencia sobre violencia familiar y las aplicaciones de las ultimas modificatorias incluyendo la ley de violencia familiar No
30364, resulta eficaz como garantía de protección de las victimas enmarcados dentro de los que se denominan poblaciones vulnerables. Asimismo, de este objetivo principal se desprendieron los siguientes objetivos específicos: Determinar de qué manera la doctrina y la jurisprudencia sobre Violencia Familiar, genera conflictos

Recibido 20/07/2021 Aprobado 10/08/2021

Este es un artículo de acceso abierto, distribuido bajo los términos de la Licencia Creative Commons Atribución 4.0 Internacional (http://creativecommons.org/licenses/by/4.0/)

1 Doctor en Derecho, Maestro en Derecho Civil de la Universidad Inca Garcilazo de la Vega. Profesor en la Facultad de Derecho de la Universidad Nacional José Faustino Sánchez Carrión y de la Universidad Nacional de Barranca. Director del Estudio Rojas Alvarado \& Abogados, ORCID: 0000-0002-6822-8402 
normativos para determinar la responsabilidad del presunto agresor en contra de las víctimas, teniendo en cuenta que la última ley exige el cumplimiento de plazos perentorios y se resuelva mediante las denominadas medidas de protección, así como que trae consigo dos nuevas modalidades de Violencia Familiar, ampliando el panorama sancionador y persecutor.

(Rodríguez, 2015) En su trabajo de investigación denominada "Vulnerabilidad y Daño Psíquico en mujeres víctimas de Violencia en el medio familiar", realizada por la Universidad de Granada. Este autor se centra en la importancia de su estudio en que las mujeres maltratadas de 31-40 años, por razones de edad tienen problemas psicológicos a los que llama daño, y es la más frecuente, y que asimismo de acuerdo a sus estudios aparece también, el daño psíquico la cual es más pronunciado, entonces cuál es la diferencia y cuál es el papel fundamental que cumple estos daños dentro de un proceso judicial en los juzgados de familia.

(Montoya, 2009)En su trabajo de investigación denominada "Criminología y violencia familiar: una aproximación a la violencia en el hogar a partir del estudio de las características del maltratador", realizada por el Centro de Investigación en Criminología de la Universidad de Castilla. El autor en primer lugar, establece un orden de agravio con respecto a las víctimas de violencia hacia la mujer siendo justamente estas el centro de este flagelo y en un segundo orden nos dice, que en muchas partes del mundo la prevención y erradicación no son temas prioritarios de los estados, a pesar de haber estudios como este que confirman que las consecuencias para la familia son devastadoras porque no solo afecta a la mujer sino también a los descendientes quienes no solo sufren los estragos de esta violencia hacia su madre, sino que, también son afectados emocionalmente trayendo un $70 \%$ de probabilidad que cuando tengan sus propias familias sigan el mismo modelo de violencia.

(Vera, 2014) En su trabajo de investigación titulada "EI marco simbólico de la Ley de Violencia Familiar y sus modificaciones", realizada por la Universidad Nacional de Trujillo. Para optar el grado académico de Maestro en Derecho con mención en Derecho Penal y Ciencias Criminológicas. Este autor se centra en la importancia de su estudio en que la ley de violencia familiar la 26260 y sus modificatorias tiene muchas deficiencias entre ellas que es retributiva porque solo se preocupa en sancionar y en agravar las penas, pero no se preocupa en prevenir el problema, así mismo de acuerdo a un estudio señala que la incidencia de la violencia psicológica es mayor que las otras modalidades de violencia, y que no se está protegiendo el bien jurídico de la integridad psíquica de las mujeres maltratadas, agregándose un proceso judicial tedioso en los tramites sobre lesiones porque se generan procesos paralelos, como en las fiscalías penales y de familia.

Legislación Internacional. - Con el tiempo, los órganos de los tratados creados para supervisar la aplicación de los tratados internacionales en materia de derechos humanos han ido asumiendo progresivamente las obligaciones de los Estados partes de hacer frente a la violencia contra la mujer. En su recomendación general No 19 (1992) sobre la violencia contra la mujer, el Comité de las Naciones Unidas (2010) para la Eliminación de la Discriminación contra la Mujer, confirmó que: "En virtud del derecho internacional y de pactos específicos de derechos humanos, los Estados pueden ser responsables de actos privados si no adoptan medidas con la diligencia debida para impedir la violación de los derechos o para investigar y castigar los actos de violencia y proporcionar indemnización". En relación con marcos jurídicos nacionales.

El Comité de las Naciones Unidas para la Eliminación de la Discriminación contra la Mujer recomendó que los Estados partes:

Velen por que las leyes contra la violencia y los malos tratos en la familia, la violación, los ataques sexuales y otro tipo de violencia contra la mujer protejan de manera adecuada a todas las mujeres y respeten su integridad y su dignidad; y

Adopten todas las medidas jurídicas y de otra índole que sean necesarias para proteger eficazmente a las mujeres contra la violencia, entre ellas, medidas jurídicas eficaces, como sanciones penales, recursos civiles e indemnización, para protegerlas contra todo tipo de violencia.

Durante su revisión de los informes de los Estados partes, los órganos de los tratados han expresado su preocupación cuando los ordenamientos jurídicos de los Estados partes carecen de legislación o de disposiciones legislativas específicas para tipificar como delito la violencia contra la mujer y/o cuando mantienen leyes discriminatorias que refuerzan la vulnerabilidad de las mujeres con respecto a la violencia. Además, han expresado preocupación sobre problemas con la legislación existente, incluidos el ámbito de aplicación y la cobertura, y por la falta de aplicación efectiva de dicha legislación.

A la luz de estas preocupaciones, los órganos de los tratados $y$, en particular, el Comité de las Naciones Unidas para la Eliminación de la Discriminación contra la Mujer, han hecho un llamamiento a los Estados partes para que garanticen que:

Se enjuicie y castigue la violencia contra la mujer

Las mujeres víctimas de violencia tengan medios inmediatos de separación y protección.

Los funcionarios públicos, especialmente el personal responsable de hacer cumplir la ley, los proveedores de servicios sanitarios, los trabajadores sociales y los profesores, estén plenamente familiarizados con las disposiciones jurídicas aplicables y sensibilizadas con el contexto social de la violencia contra la mujer. 
Cuarta Conferencia Mundial sobre la Mujer (Beijing, 1995), 17 Informe de la Cuarta Conferencia Mundial sobre la Mujer, Beijing, China, 4-15 de septiembre de 1995 (publicación de las Naciones Unidas, Nº de Venta: S.96.IV.13), párr. 124.- insta a los gobiernos a:

Introducir sanciones penales, civiles, laborales y administrativas en las legislaciones nacionales con el fin de castigar y reparar los daños causados a las víctimas.

Adoptar, aplicar, revisar y analizar las leyes pertinentes a fin de asegurar su eficacia para eliminar la violencia contra la mujer, haciendo hincapié en la prevención de la violencia y en el enjuiciamiento de los responsables.

Adoptar medidas para garantizar la protección de las mujeres víctimas de la violencia, el acceso a remedios justos y eficaces, inclusive la reparación de los daños causados, la indemnización y la cura de las víctimas y la rehabilitación de los agresores.

Legislación Nacional. - En nuestro ordenamiento el T.U.O de la Ley $N^{\circ} 30364$ (Ley para Prevenir, Sancionar y Erradicar la Violencia contra las Mujeres y los Integrantes del Grupo Familiar) y su Reglamento configuran un marco normativo de protección a las víctimas de la violencia familiar en nuestro país que señalan:

Reconocimiento de los derechos de la mujer frente a la violencia familiar estableciendo mecanismos, medidas y políticas integrales de prevención, atención y protección de las víctimas, así como reparación del daño causado; y dispone la persecución, sanción y reeducación de los agresores sentenciados con el fin de garantizar a las mujeres y al grupo familiar una vida libre de violencia asegurando el ejercicio pleno de sus derechos.

\section{Antecedentes de la Violencia Familiar}

(Coulanges, 2016) En el año 200 a.c. Marco Poncio Catón decía19: "El marido es el juez de su mujer, su poder no tiene límites, puede lo que quiere. Si ella ha cometido una falta, la castiga, si ha bebido vino la condena; si ha tenido comercio con otro hombre, la mata" (p.113).

(Pachas, 2015) En el derecho consuetudinario -siglo XIV- se consideraba que "está bien que el hombre pegue a su mujer sin matarla y sin herirla, cuando desobedece al marido, En la historia del Perú antiguo los cronistas describen a la mujer como alguien que vivía sumisa y pendiente del marido, ya que le servía en el hogar, trabajaba en el campo, llevaba cargas, lo acompañaba en la guerra y en otras tareas, es decir, ayudaba al hombre, En esta línea equivocada acerca de la mujer, también tuvo acogida en nuestra legislación el Código Civil de 1852 permitía corregir moderadamente a la esposa, y el de 1936 que lo reemplazó, otorgaba mayores derechos el varón en las decisiones del hogar, " (p.20).
(Pachas, 2015) Desde tiempos inmemoriales, siempre hubo una corriente de supremacía masculina, no sólo por su naturaleza física sino porque se impone a la fuerza contra la voluntad de la mujer.

En nuestro país, este problema de la violencia familiar que afecta directamente a la mujer y a la niñez, siempre estuvo presente pero invisible, todos los actos de violencia familiar quedaban en ese ámbito y nunca se hacía público. Esta violencia familiar está íntimamente vinculada a normas y patrones socioculturales y en una cultura patriarcal que subordina y discrimina a la mujer, estando presentes en determinadas familias, el "machismo" que impone su voluntad en muchos casos sin mayor consideración ni sentido común en evidente perjuicio de la mujer que es discriminada no sólo en el hogar, sino también en el ámbito laboral, social y cultural; a pesar de ello, existe una verdadera reivindicación y protagonismo de la mujer que por propios méritos ha logrado progresos en su vida personal, familiar, profesional y social, Cabe resaltar que no sólo existe la violencia contra la mujer, sino que también existe la violencia contra el varón y contra los niños. Algunos investigadores consideran que la violencia contra el hombre es un problema social serio, porque aunque se haya prestado mayor atención a la violencia que se ejerce contra las mujeres, sería posible argumentar que la violencia contra los hombres en varios contextos es un problema social sustancial digno de atención; sin embargo, éste sería un tabú social y un fenómeno distinto a la violencia contra las mujeres y debe analizarse como tal, debido a que su naturaleza, causas y consecuencias serían distintas, así como los espacios en que se manifiesta. (p.21).

\section{Concepto}

(Vera, 2014) De todas estas definiciones, podemos concluir que el término "Violencia familiar" se refiere al maltrato que se da en la familia, por parte de sus integrantes y terceros relacionados con aquella, que involucra un plexo amplio de conductas (por acción u omisión) de parte del sujeto agresor, que afectan una variedad de derechos y sentimientos de la persona que las padece y que se traduce en perjuicios de tipo físico, psicológico y sexual, los que se dan concatenados o unidos uno al otro por un sutil enlace, siendo muy difícil diferenciar en la práctica una única lesión a los derechos que se protege. Por ejemplo, el abuso sexual concurre violencia física y psicológica y ocasiona graves secuelas y perjudican la salud mental de la víctima (p.22).

La actitud de las autoridades. - (Dador, 1998) Otro importante factor que mantiene irresolutos muchos casos de violencia familiar es la actitud de las autoridades hacia este problema. Con frecuencia los policías, los jueces de paz, los fiscales y las autoridades de la comunidad tienen sobre la violencia familiar las mismas ideas que hemos presentado. Por eso las víctimas tienden a pensar que es inútil presentar una denuncia (p.89). 
(Calle, 2004) Es fundamental que todas las autoridades involucradas tengan conciencia de que su lentitud o insensibilidad pueden contribuir a agravar las situaciones de violencia familiar (p.22).

Regulación en el Ordenamiento Jurídico Peruano y su tratamiento Internacional.

(Pachas, 2015) La Convención de Naciones Unidas de los Derechos del niño (CDN), establece cuatro principios fundamentales que deben situar $u$ orientar todas las acciones institucionales en materia de infancia:

Principio de no discriminación (Artículo 2 de la CDN): Este principio señala que "los Estados partes respetarán los derechos enunciados en la presente Convención y asegurarán su aplicación a cada niño sujeto a su jurisdicción, sin distinción alguna, independientemente de la raza, el color, el sexo, el idioma, la religión, la opinión política o de otra índole, el origen nacional, étnico o social, la posición económica, los impedimentos físicos, el nacimiento o cualquier otra condición del niño, de sus padres o de sus representantes legales."(p.39).

Principio del Interés superior del menor (Artículo 3 de la CDN).

Principio de participación, es decir, el derecho del menor a ser escuchado (Artículo 12 de la CDN): "Los Estados Partes garantizarán al niño que esté en condiciones de formarse un juicio propio, el derecho de expresar su opinión libremente en todos los asuntos que afectan al niño, teniéndose debidamente en cuenta las opiniones del niño, en función de la edad y madurez del niño" (p.39).

Derecho a la vida, la supervivencia y el desarrollo (Artículo 6 de la CDN) (p.39).

(Pachas, 2015) En el Sistema Interamericano de Derechos Humanos, la Convención Americana de Derechos Humanos establece en el artículo $1^{\circ}$ que "los Estados Parte se comprometen a respetar los derechos y libertades reconocidos en ella y a garantizar su libre y pleno ejercicio a toda persona que esté sujeta a su jurisdicción, sin discriminación alguna (...)".

El artículo 5.1 señala que "toda persona tiene derecho a que se respete su integridad física, psíquica y moral" y el artículo 25.1 que "toda persona tiene derecho a un recurso sencillo y rápido o a cualquier otro recurso efectivo ante los jueces o tribunales competentes, que la ampare contra actos que violen sus derechos fundamentales, Asimismo, la Convención Interamericana para Prevenir, Sancionar y Erradicar la Violencia Contra la Mujer "Convención de Belém do Pará"47, establece en el artículo 1, que la violencia contra la mujer es "cualquier acción o conducta, basada en su género, que cause muerte, daño o sufrimiento físico, sexual o psicológico a la mujer, tanto en el ámbito público como en el privado, Asimismo El Estado tiene el deber de brindar recursos judiciales y tales recursos deben ser idóneos para remediar las violaciones de derechos humanos denunciadas48. En dicho marco, los
Estados tienen el deber de cumplir con cuatro obligaciones: la prevención, la investigación, la sanción y la reparación de las violaciones de los derechos humanos y evitar la impunidad" (p.39).

\section{¿Existe el delito de Violencia Familiar?}

La discusión que acaba de zanjar la norma, es que la lesión cometida por el agresor, aunque, este por debajo, del límite de ser faltas, esta se considere dentro de los parámetros y agravantes señalados en la Ley 30364, es decir, genera un proceso penal, que tiene otras repercusiones, asimismo no es necesaario que el victimario y la victima pertenezcan a la misma unidad familiar, no siendo necesario también tener hijos o tener una convivencia cotidiana y permanente.

Delito de lesiones psicológicas derivadas de violencia Familiar.

(Ley, 2015) La modificación más importante es la incorporación del artículo 124-B al Código Penal. En este precepto se establece que el nivel de la lesión psicológica será determinado mediante valoración realizada de conformidad con el instrumento técnico oficial especializado que orienta la labor pericial. En tal sentido, se precisa que se considerará falta de lesiones leves al nivel mínimo de daño psíquico, delito de lesiones leves al nivel moderado de daño psíquico y delito de lesiones graves al nivel grave o muy grave de daño psíquico (p.1).

(Caro, 2016) Desde el punto de vista de la regulación, aquí lo que se ha generado es una suerte de "norma penal en blanco" porque el recientemente incorporado artículo 124-B del Código Penal establece que el nivel de la lesión psicológica será determinado mediante una valoración realizada de conformidad con el instrumento técnico oficial especializado que orienta la labor pericial. El problema es que este instrumento técnico oficial no es una ley ni un decreto supremo ni una resolución, ni una norma del Estado con carácter impersonal, general y abstracto; es más bien una suerte de instrumento técnico donde se establecerían una serie de criterios para diferenciar las faltas, lesiones leves y lesiones graves, en este caso, psicológicas.

(Caro,2016) Por ello, considero que el legislador no ha hecho un buen trabajo para determinar la agresión psicológica. Lo más aconsejable, en estos casos, es utilizar un sistema de numerus apertus, en el cual pueda contemplarse, por ejemplo, diez situaciones de casos de daños psicológicos, de tal manera que, por el número de situaciones concurrentes, pueda hablarse de lesiones leves, graves o incluso de faltas. En resumen, hubiera sido mejor que la propia ley otorgue criterios más específicos y mayores detalles. Más aún porque esto va a determinar la vía procesal pertinente porque mientras las faltas se ven ante el juez de paz, los delitos se ven ante la fiscalía. Si no hay criterios claros para poder diferenciar, entonces, esto va a generar problemas procesales. 
La Investigación está sustentado en las normas legales siguientes:

\section{Declaración Universal de los Derechos Humanos}

Artículo 1.- todos los seres humanos nacen libres e iguales en dignidad y derechos y (...) deben comportarse fraternalmente los unos con los otros.

\section{- $\quad$ Constitución Política del Perú}

Articulo 4.- protección a la Familia, promoción del matrimonio de la comunidad y del Estado, protegen especialmente al niño al adolescente a la madre y al anciano en situación de abandono....

Ley $N^{\circ} 30364$ - Ley Para Prevenir, Sancionar y Erradicar la Violencia Contra las Mujeres y los Integrantes del Grupo Familiar.

Artículo 1. "La presente ley tiene por objeto prevenir, erradicar y sancionar toda forma de violencia producida en el ámbito público o privado contra las mujeres, y contra los integrantes del grupo familiar, en especial, cuando se encuentran en situación de vulnerabilidad, por la edad o situación física como las niñas, niños, adolescentes, personas adultas mayores y personas con discapacidad".

Artículo 5. "La violencia contra las mujeres es cualquier acción o conducta que les causa muerte, daño o sufrimiento físico sexual psicológico por su condición de tales, tanto en el ámbito público como en privado".

Artículo 6. "La violencia contra cualquier integrante del grupo familiar es cualquier acción o conducta que le cause muerte, daño o sufrimiento físico, sexual o psicológico y que se produce en un contexto de una relación de responsabilidad, confianza o poder, de parte de un integrante a otro del grupo familiar".

Decreto Legislativo $N^{\circ} 1323$ - Decreto Legislativo que Fortalece la Lucha contra el Feminicidio, la Violencia Familiar y la Violencia de Genero.

Convención Interamericana para prevenir, sancionar y erradicar la violencia contra la mujer "Convención De Belem Do Para" Articulo 1,2,3 y 4.

Importancia. - este trabajo es importante porque dará a conocer a la comunidad universitaria, a la comunidad jurídica y a todas las personas, como se relacionan la doctrina, la jurisprudencia, la ley de Violencia Familiar 300364 y la vulneración de los derechos fundamentales de las víctimas, enmarcadas por la nueva ley como poblaciones vulnerables, Es interesante porque la colectividad a la que pertenecen todas las personas a partir de este estudio pueden adquirir conciencia y conocimiento del problema y que tanto los operadores de justicia y de los legisladores reflejan una falta de conocimiento de la realidad, además de no contar con la logística necesaria por las indiferencias y ausencia de políticas públicas de los gobiernos de turno.

\section{MATERIALES Y MÉTODO}

Los materiales utilizados son las casaciones de nuestra Corte Suprema de Justicia y el método utilizado es descriptivo y hermenéutico, por ejemplo y si bien es cierto que en las casaciones del 2012 y 2018, se resolvieron bajo el amparo de la ley Casación N ${ }^{\circ} 2350$ 2012-LIMA (Cacerés, 2015). Vale la pena destacar un caso en el que la presunta víctima no es la mujer. En la Casación $N^{\circ}$ 2350-2012-LIMA publicada en el diario oficial el 28 de febrero de 2014, quedó en evidencia cómo se puede forzar al sistema para establecer un maltrato psicológico que no se basaba en pruebas fundamentales como, precisamente, la pericia psicológica. Con fecha 13 de junio de 2013, la Sala Civil Permanente de la Corte Suprema de Justicia de la República resolvió el recurso de don César Alberto Ninanya Gonzales contra el fallo expedido por la Segunda Sala Especializada en Familia de la Corte Superior de Justicia de Lima, la que, revocando la sentencia apelada de fecha 25/11/2011, declaró infundada la demanda interpuesta contra Mirela Angélica Cruz Figueroa. Cabe señalar que, ante la Segunda Fiscalía Mixta de La Molina y Cieneguilla, el citado actor interpuso demanda por violencia familiar en la modalidad de maltrato psicológico contra la citada Mirela Angélica Cruz Figueroa. La fiscal provincial sostuvo los siguientes fundamentos de hecho: a) el 31 de enero del 2009, el señor Ninanya Gonzales y Mirela Angélica Cruz Figueroa se denunciaron mutuamente por violencia familiar, debido a los maltratos psicológicos al interior del hogar; b) don César Ninanya Gonzales refiere que su cónyuge de manera constante lo ofendía y que, días después de presentada la denuncia, esta abandonó el hogar conyugal llevándose consigo a sus tres menores hijos (p.109).

\section{CASACIÓN 1977-2018 LORETO VIOLENCIAFAMILIAR} señala: Consecuentemente, el derecho al debido proceso y la tutela jurisdiccional efectiva constituyen principios consagrados en el inciso 3, del artículo 139, de la Constitución Política del Estado, los cuales comprenden a su vez, el deber de los jueces de observar los derechos procesales de las partes y el derecho de los justiciables a obtener una resolución fundada en derecho ante su pedido de tutela en cualquiera etapa del proceso.

De ahí que dichos principios se encuentren ligados a la exigencia de la motivación de las resoluciones judiciales, prevista en el inciso 5 del referido artículo constitucional, esto es, que los jueces y tribunales expliciten en forma suficiente las razones de sus fallos, con mención expresa de los elementos fácticos y jurídicos que los determinaron. Por tanto, la contravención de las normas que garantizan el derecho a un debido proceso se da cuando en el desarrollo del mismo, no se han respetado los derechos procesales de las partes, se han obviado o alterado actos de procedimiento, la tutela jurisdiccional no ha sido efectiva y/o el órgano jurisdiccional deja de motivar sus decisiones o lo hace en forma incoherente, en clara transgresión de la normatividad vigente y de los principios procesales. 
En la casación 1977-2018 Loreto sobre violencia familiar antes referida en el punto noveno:

Aunado a los parámetros descritos en el considerando anterior, es pertinente señalar que en el caso concreto no resulta suficiente para imputar responsabilidad en el demandado respecto de la violencia psicológica, por el solo dicho de la demandante y las pericias psicológicas, sino que en este caso resulta relevante la corroboración de lo expresado por la demandante en relación a los insultos proferidos, más si estos se hicieron en una institución pública y en presencia de otras personas; por lo cual, esta Sala Suprema considera que, las decisiones emitidas en los casos de violencia familiar deben tener la exigencia de una suficiente actividad probatoria que nos lleve a determinar de forma objetiva la responsabilidad del demandado en los hechos imputados, y para dicho fin, resulta fundamental realizar un despliegue probatorio sólido para sustentar la decisión, más aún, que en el tema materia de análisis, donde si bien estamos ante la existencia del certificado médico legal Nº 002580-VF-PS y la Evaluación Psicológica Nº05761-2014-VF, practicado por el Instituto de Medicina Legal de Loreto, estos elementos resultan insuficientes per se para lograr determinar de manera fehaciente la responsabilidad del denunciado, atendiendo a las premisas antedichas.

Así tenemos, la STC 0618-2005-PHC/TC14, que señala: "(...) el principio de libre valoración de la prueba en el proceso penal que corresponde actuar a los Jueces y Tribunales; que la sentencia condenatoria se fundamente en auténticos hechos de prueba, y que la actividad probatoria sea suficiente para generar en el Tribunal la evidencia de la existencia no sólo del hecho punible, sino también la responsabilidad penal que en él tuvo el acusado y así desvirtuar la presunción".

Además de lo dicho, también es pertinente mencionar que la sentencia contenida en la Casación 2245-2016 Lima, sobre violencia familiar, ha considerado en el fundamento octavo que: "Examinada la sentencia de vista, se advierte que si bien el Ad quem ha sustentado sustancialmente su pronunciamiento sobre la base del certificado médico legal practicado en la agraviada, no obstante esta Sala Suprema considera que el referido medio probatorio resulta no solo insuficiente sino además diminuto toda vez que con ello no se logra determinar palmariamente la responsabilidad objetiva del demandado."

Asimismo, nuestra constitución política del Perú señala en su artículo cuarto. - "la comunidad y el estado protegen especialmente al niño, al adolescente a la madre y al anciano en situación de abandono. También p0rotegen a la familia y promueven al matrimonio. Reconocen a estos últimos, como instituto naturales y fundamentales de la sociedad. La forma del matrimonio y las causas de separación y de disolución son reguladas por la ley" advertimos, el mensaje del artículo, sin embargo, la realidad es otra, y uno de los factores importancias del por qué el sistema de justicia no funciona es porque también las políticas públicas están muy distantes de estar acorde con lo que señala nuestra constitución, manteniendo un sistema de justicia retributivo, que a la luz de los hechos no funciona.

En la recopilación de datos se utilizaron los medios técnicos adecuados que permitieron captar la real dimensión de la problemática planteada; razón por la cual de entre las técnicas de recopilación de datos tenemos: el análisis documental y la Observación científica. Los instrumentos a emplear en la presente investigación son los siguientes:

Observación: Técnica que nos permite apreciar cómo se desenvuelve el fenómeno estudiado; vale decir, que a través de ella se llega a conocer el grado de aplicación de la institución jurídica en estudio.

Acopio Documental: Para la ejecución de la presente investigación se efectuará la extracción de datos preexistentes en el Juzgado de Familia y Fiscalía Penal del Distrito Fiscal de Huaura.

Bibliográficas: Se utiliza para llevar a cabo la revisión y el análisis de la bibliografía relacionada con el tema objeto de estudio, siendo aplicable en todas las fases de la investigación. La información requerida fue obtenida de las Bibliotecas Especializadas de las Facultades de Derecho de las Universidades Locales y nacionales, páginas Web.

\section{RESULTADOS}

El resultado de la investigación desarrollada fue lo siguiente: en primer lugar, una de las causas:

En primer lugar, uno de los aspectos relevantes que se busca es la eficacia en el proceso por violencia familiar, sin embargo, se advierte según la jurisprudencia y doctrina que no constituye una garantía de protección de las víctimas, inclusive desde los actos preliminares y que además no existe un consenso mayoritario para sostener que esta ley garantiza un debido proceso para ambas partes. Las normas que se expiden sobre violencia familiar, no deben responder a un contexto coyuntural; sino a una razón lógica y jurídica dentro de una política a favor de la familia en tanto a su protección, como la educación, valores, una verdadera prevención y se luche contra la violencia familia, desde adentro hacia afuera, es decir cuando sus miembros conocen sus derechos y respetan el de los otros, se debe desechar el criterio de penalizar ya que esta solo para buscar la persecución y sanción del agresor.

En segundo lugar una de las causas que incide a que no se cumpla con el debido proceso, vulnerando el derecho de la igualdad de armas entre las partes, es la búsqueda, por la ley de violencia familiar 30364, de la inmediata solicitud de las medidas de protección en favor de la presunta víctima, advirtiéndose generalmente que el presunto agresor no es notificado de la denuncia ante la PNP, y de la remisión del expediente al Poder Judicial, quien resuelve dar de las medidas de protección en favor de la presunta víctima, el presunto agresor generalmente 
no hizo uso de su derecho fundamental a una debida defensa, o de lo contrario, en el caso de la detención del presunto agresor generalmente por un nuevo hecho, recién se llega a enterar de que tiene medidas de protección en su contra, debiéndose ordenar su libertad inmediata, creando más bien en la victima no solo indefensión sino, desprotección y desconfianza en la administración de justicia, razón por la cual los operadores de justicia, al fijar un acto de violencia familiar deben ser los más diligentes y acuciosos posible, teniendo a la vista los informes del equipo multidisciplinario, a fin de que posteriormente no se convierta en irreparable la violencia familiar.

En tercer lugar, es evidente que según jurisprudencia de la corte suprema de justicia de la república sala civil permanente casación 1977-2018 Loreto violencia familiar antes citada, se advierte que un proceso que se inicia en el año 2014 por violencia familiar, llega a resolverse vía casación después de cuatro años aproximadamente, señalando inclusive en la resolución que se resuelve declarar fundado el recurso de casación interpuesto por la parte demandada, nula la sentencia de vista e insubsistente la sentencia apelada que declaro fundada la demanda de violencia familiar en la modalidad de maltrato psicológico de primera instancia, y ordenaron que el juez de la causa previo cumplimiento de los expresado emita nuevo fallo. Por lo que se advierte dos temas que genera este problema que no solo atenta contra las partes es decir los justiciables, el primero es el tema, de que si bien es cierto que la jurisprudencia antes señalada viene de un caso se trata de un proceso de violencia familiar enmarcado en El Texto Único Ordenado de la Ley de Protección frente a la Violencia Familiar Ley $\mathrm{N}^{\circ} 26260$, siendo la última ley 30364, es de fecha, 22 de noviembre del 2015, Ley para prevenir, sancionar y erradicar la violencia contra las mujeres y los integrantes del grupo familiar.

En cuarto lugar de acuerdo a lo señalado en la jurisprudencia y a lo señalado por la doctrina, pues para evidenciar cuando estamos ante un daño psíquico o no, es importante conocer esta diferencia en la emisión de un informe psicológico o pericia psicológica, ya que tiene que crear convicción en el Juez de Familia, quien tiene que tener todos los recaudos necesarios para poder graduar no solo las medidas de protección sino para poder motivar de acuerdo la sentencia, por ello es importante conocer cunado estamos en el margen de diferenciación entre violencia psicológica leve, moderado o severo que señala la ley, y también quien es el funcionario responsable de este informe psicológico, habiendo aparecido los Centros de Emergencia Mujer con ciertas limitaciones es decir no tienen la facultad de señalar en sus informes el daño psicológico, quien está reservado solo para el perito psicólogo.

En quinto lugar, Esta investigación, la jurisprudencia y la doctrina, al realizar el contraste con nuestra realidad, se hace evidente lo que señala el autor, debido a que las políticas públicas de los gobiernos de turno no reflejan no solo viabilidad, sino que también carecen de la educación a la prevención y más bien se concentra en la persecución del agresor, característica de un sistema de justicia retributivo, en el cual estamos inmersos. En donde el operador de justicia en algunos casos, tiene una actuación inquisitiva, en donde además, está ausente la sociedad civil, la falta de políticas públicas favorables con educación y prevención, por ello afecta la relación de padres a hijos, confirmándose como población vulnerable, no solo en el aspecto económico sino también de manera emocional, evidenciándose una contraposición legal, debido a que colisiona con principios constitucionales, la doctrina de protección integral, la convención internacional de los derechos del niño, derechos humanos, entre ellos el interés superior del niño.

\section{DISCUSIÓN}

Desde este punto de vista el presente trabajo de investigación, es importante en debido a que analizamos los distintos casos que se han presentado sobre violencia familiar y que pese a las normas que permiten una mayor protección de las víctimas, en realidad, no han disminuido, el presente trabajo de investigación es importante porque permitirá la aplicación de métodos de investigación jurídica - científica, que genere conocimientos válidos dentro del área del derecho, especialmente en familia. familia como institución está en crisis y por ende la institución de la violencia familiar viene constantemente siendo modificada en cuanto a las normas sustantivas y procesales pero que no han tenido una eficacia, de allí que actualmente esta institución ha tomado gran notoriedad e importancia según las doctrinas y jurisprudencias.

La jurisprudencia y las leyes, en materia de violencia familiar como la ultima Ley $N .^{\circ} 30364$, carecen de una verdadera política de prevención, por lo que este flagelo no solo tiende a aumentar a nivel nacional, sino que muchas veces termina en feminicidio, debido a que una de las causas que originan esta tendencia en nuestra realidad peruana es que no se tiene una cultura de prevención, tenemos programas, comisiones especializadas, normas nacionales $s$ e internacionales pero que carecen de efectividad debido a que solo se dedican a imponer drasticidad en las leyes como único método de solución, se configura una vez más, el inoperante y a la vez imperante sistema de justicia que actualmente tenemos.

La justicia retributiva, sigue presente en nuestras mentes y quehacer diario, por lo que no se garantiza el debido proceso por violencia familiar y que además no constituye una garantía de protección de las víctimas, y los actos de violencia familiar se han transformado en un fenómeno social que se encuentra presente y aumenta en todas las estructuras sociales. El Estado solo atina a los cambio o modificaciones de las normas legales a las cuales se les puede denominar como paliativos, que no tendrá un efecto reductivo de los altos índices de violencia familiar. 
Los legisladores solo se preocupan a partir de los últimos acontecimientos conocidos a través de los medios de comunicación sobre violencia familiar, por lo que su reacción es tardía, sin una convicción y menos con una verdadera educación a la prevención, garantizando el cumplimiento del principio contenido en el artículo cuarto de nuestra constitución política del Perú.

Por último, la ley no es clara en delimitar la violencia familiar en la modalidad de maltrato psicológico, sus graduaciones como leve, moderado, severo, el daño psíquico, los atributos y funciones de los psicólogos de los centros de emergencia mujer, si es leve, necesariamente tiene que emitirse las medidas de protección, llegando el proceso hasta el conocimiento de la fiscalía penal, el respeto al debido proceso, son temas que no están claras por la ley.

\section{REFERENCIAS BIBLIOGRÁFICAS}

La Constitución Política del Perú. 1993

Ley de Violencia Familiar 30364

Decreto Legislativo $\mathrm{N}^{\circ} 1323$

Convención Internacional de los Derechos del Niño

Convención Belén do Para

Código de los Niños y Adolescentes

\section{Código Civil Peruano}

Dador, G. Y. (1998). La violencia contra la mujer. Aplicación de la Ley de Violencia Familiar desde una perspectiva de género: estudio de casos. Lima: Movimiento Manuela Ramos.

RODRIGUEZ, (2015) En su trabajo de investigación denominada "Vulnerabilidad y Daño Psíquico en mujeres víctimas de Violencia en el medio familiar", realizada por la Universidad de Granada. (p.220).

MONTOYA, (2009) en su trabajo de investigación denominada "Criminología y Violencia familiar: una aproximación a la violencia en el hogar a partir del estudio de las características del maltratador", realizada por el Centro de Investigación en Criminología de la Universidad de Castilla. (p.200).

VERA, (2014) En su trabajo de investigación titulada "EI marco simbólico de la Ley de Violencia Familiar y sus modificaciones", realizada por la Universidad Nacional de Trujillo. Para optar el grado académico de Maesten Derecho con mención en Derecho Penal y Ciencias Criminológicas (p.13,17,p.90)

SANCHEZ, (2013) En su trabajo de investigación titulada "Factores determinantes de la violencia familiar y sus implicancias", realizada por la Universidad Nacional Mayor de San Marcos. Para optar el grado académico de Magister en Derecho, con mención en Derecho Civil y Comercial (p.77,78,79).
COULANGES, (2006) Antecedentes de la violencia (p.113).

CARO CORIA, Carlos. "No está claro qué debemos entender por lesiones psicológicas contra la mujer". http://laley.pe/not/2934/-no-esta-claro-que-debemosentender-por-lesiones-psicologicas-contra-la-mujer-/. 20.12.2016

Calle, W. A. (2004). Violencia Familiar en la región andina. Análisis Comparado de la legislación, https://www.unifr.ch/ddp1/derechopenal/obraspo rtales/op_20080612_08.pdf.

ley, L. (2018). Modifican el Código Penal: conozca la nueva regulación del delito de feminicidio. Gaceta Jurídica, http://laley.pe/not/5746/modifican-elcodigo-penal-conozca-la-nueva-regulacion-deldelito-de-feminicidio-l.

Llanos, B. A. (2014). La familia en el Código Civil Peruano. Foro Juridico, http://revistas.pucp.edu.pe/index.php/forojuridic o/article/viewFile/18507/18747.

Pachas, A. G. (Noviembre de 2015). Violencia Familiary régimen de visitas para el agresor en el ordenamiento Peruano. Universidad de Piura, pág. https://pirhua.udep.edu.pe/bitstream/handle/110 42/2323/DER 036.pdf?sequence=1.

Sánchez, O. O. (2013). Factores determinantes de la Violencia Familiar y sus implicancias. Universidad Nacional Mayor de San Marcos, http://cybertesis.unmsm.edu.pe/bitstream/handl e/cybertesis/3725/Orna so(2).pdf;jsessionid=7F D28878D0AB08379AF5D839C96D9677?sequence= 1 .

Solis, A. M. (2017). Medidas de protección que otorga el Primer Juzgado de Familia frente a las víctimas de Violencia Familiari en la ciudad del Cusco Perioso 2016. Universidad Andina del Cusco, http://repositorio.uandina.edu.pe/bitstream/UAC /1117/3/Almendra_Gina_Tesis_bachiller_2017.p df.

JUR ISPRUDENCIA DEL TRIBUNAL CONSTITUCIONAL DELPERÚ

STC: 03378-2019-PA/TC/ICA

STC 0618-2005-PHC/TC14

CASACIONES:

$\mathrm{N}^{\mathrm{a}}: 2215-2017$ DEL SANTA

N²350-2012-LIMA

Na 1977-2018 LORETO

$N^{\circ} 2737-2015$ Cusco 